\section{Visibility in Meteorology:}

the Theory and Practice of the Measurement of the Visual Range. By W. E. Knowles Middleton. Pp. viii + 104. (Toronto : University of Toronto Press; London: Oxford University Press, 1935.) $8 s .6 d$. net.

"How far can I see to-day ?" This question "assumes in the minds of the aviator and navigator an importance greater, perhaps, than that of any other meteorological matter. For such men it takes the place of that great public question which Sir Napier Shaw has called the fundamental problem of meteorology-'Will it rain to-morrow ?'" Thus far the author who, in his introductory chapter, remarks very pertinently that the term visibility was not well chosen, the visibility of an object being an expression of the ease with which it can be seen, whereas "visibility" is a distance, and moreover, is the distance at which an object cannot be seen.

Methods for the estimation of visual range and a knowledge of the factors on which visual range depends are subjects of the first importance for those concerned with matters of transport, and the appearance of this monograph is very timely. Beginning with a general account of the behaviour of light in the atmosphere, the author proceeds to a discussion of the appearance of objects and of light sources seen through the lower atmosphere, linking up this discussion to calculations of the visual range by day of black, white, grey and coloured objects, the visual range of objects by moonlight and starlight, and the visual range of light-sources at night.

So far the exposition is general and theoretical, and the author now proceeds to a description of experimental work, of the estimation of visual range in practice, of the dependence of visual range on the other meteorological elements and of a rational scale of visual ranges.

The literature of the subject is already wide (the author provides a bibliography of about a hundred and fifty items) and scattered, and the author has done a real service in bringing together this literature and analysing it critically in a manner clear, stimulating and concise.

A. F.

\section{Anatomy of the Rat}

By Eunice Chace Greene. (Transactions of the American Philosophical Society, New Series, Vol. 27.) Pp. $x i+370$. (Philadelphia : American Philosophical Society; London : Oxford University Press, 1935.) $22 s$. $6 d$. net.

THIs book on the topographical anatomy of the rat is more detailed than that on any other laboratory or domestic animal. In addition to such systems as are usually treated at length in a dissecting manual, special attention has been devoted to the circulatory, nervous and endocrine systems. Thus there is a wealth of information for the biochemist and pathologist, no less than the anatomist, inasmuch as the Wistar rat has not only become the most common experimental animal, but has also attained the position of the animal presenting the highest standard of accuracy in anatomical description.
Fundamentals of Biochemistry :

in relation to Human Physiology. By T. R. Parsons. Fifth edition. Pp. xii +453. (Cambridge: W. Heffer and Sons, Ltd., 1935.) 10s. $6 d$. net.

Mr. PARSons' original aim was to produce a theoretical treatise on biochemistry containing much less in formation than is given in the larger treatises but enough to describe in a continuous story the principles of an involved and growing subject. The book is now in its fifth edition, showing that it has met a demand, and it remains chiefly to note that the fruitful progress which is being made has enabled new sections to be recorded dealing with subjects which had long been thought to be of the greatest complexity. These relate to the chemistry of muscle metabolism, of the sex hormones and of the flavines. The speed at which new discoveries are being made in these and other fields of inquiry which are fashionable for the moment is quite remarkable; it con. trasts with the lack of progress in certain other sections-at least this is the impression which the reviewer has gained from his perusal of the book.

\section{The Philosophy of a Biologist}

By Prof. J. S. Haldane. Pp. xii +155. (Oxford: Clarendon Press ; London : Oxford University Press, 1935.) 6s. net.

THIs little monograph may be considered almost as the philosophical testament of a distinguished biologist. In it he gives his ultimate conclusions based on a lifetime of eminent achievements in the biological field. After a searching, but sympathetic, criticism of some conclusions based on physics, biology and psychology, Prof. Haldane asserts that the real universe is a universe of personality and the manifestation of God; and that its scientific aspects are only partial interpretations of it, its imperfect nature being revealed by philosophical criticism. No doubt materialists and mechanicists would take exception to some of the arguments or appreciations put forward by the author; but they would recognise no less readily the sincerity of purpose and generous ideals of a great mind who is now mourned by his intellectual peers throughout the world.

T. G.

\section{Handbook of Botanical Diagrams}

By Dr. Blodwen Lloyd. Pp. 112. (London: University of London Press, Ltd., 1935.) $8 s .6 d$.

DR. LLOYD's book contains a collection of good and well-reproduced diagrams to illustrate the usual firstyear university course in botany. It therefore covers the syllabuses for Intermediate Science, First Year Medical, and Higher School Certificate examinations.

Although the whole work is well produced and attractive, it is very difficult to realise its usefulness. Not one of the diagrams would be found lacking in a text-book of this standard, though, of course, these illustrations are naturally reproduced on a larger scale. It is difficult to prevent students copying text-book diagrams; but it is a pity to encourage it, as this book certainly does. In any event, it can serve only as a supplement to a text-book, and as such, the price is rather high. 